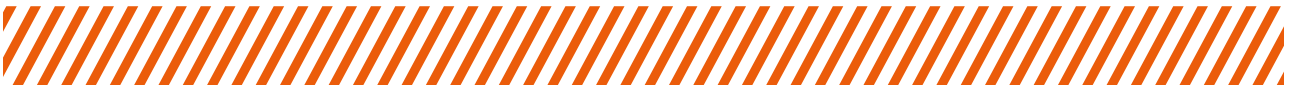

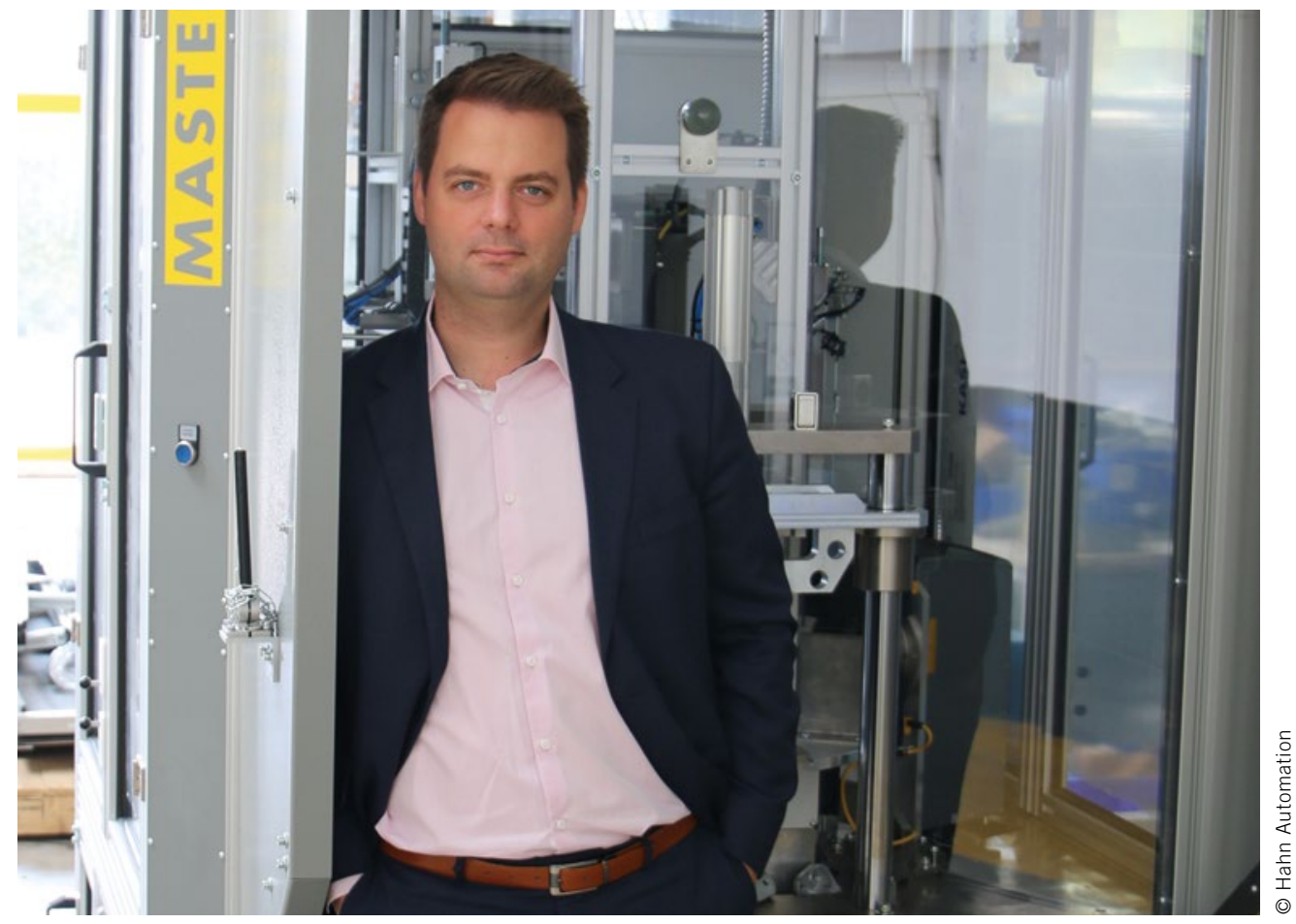

Philipp Klaschka

CEO USA der Hahn Automation $\mathrm{GmbH}$

\section{Globalisierung trifft Sondermaschinenbau}

Sondermaschinen werden selten mehrmals gebaut, meistens sind es Unikate. Die Maschinen und die damit abgebildeten Produktionsprozesse müssen immer an die zu produzierenden Artikel angepasst oder sogar komplett neu entwickelt werden.

Zudem ist es für global agierende Kunden des Sondermaschinenbaus notwendig, ihre Produktion (unter anderem aus logistischen und politischen beziehungsweise regulativen Gründen) auf die jeweiligen lokalen Märkte anzupassen. Unter dem Druck der Markentreue und somit der globalen Qualitätsabteilungen müssen diese Firmen gewährleisten, dass dieselben Teile, die zum Beispiel in China und Deutschland hergestellt werden, auch tatsächlich qualitativ gleich sind, was aufgrund der weltweit sehr unterschiedlichen Qualität beispielsweise bei Stählen oder anderen Materialien alles andere als trivial ist. Gleiche Qualität setzt auch voraus, dass der Produktionsprozess identisch ist oder zumindest extrem ähnlich. In aller Regel ist es so, dass ein Unternehmen an weltweit verteilten Standorten unabhängig voneinander die Produktionsmaschinen lokal kauft. Folglich zahlt es für das Design doppelt und wird zudem zwei nicht identische Maschinen erhalten. Gut organisierte Firmen koordinieren deshalb ihre Einkäufe und versuchen so, unnötige Mehrkosten zu vermeiden, indem sie Baupläne nur ein Mal entwickeln lassen und diese dann weltweit an andere Auftragnehmer weitergeben. Doch auch das ist nicht ohne Fallstrick: Zwar spart das dem Einkauf doppelte Entwicklungskos- ten, aber zulasten der Produktionsabteilung der anderen Länder, die nun Partner haben, die sich nicht in den Details des Designs auskennen. Somit wird auch hier Lehrgeld unnötig doppelt bezahlt. Ideal wäre hier ein global agierender Maschinenhersteller, der alle Standorte mit identischen Maschinen beliefern kann. Denn solange die Teile auf einer identischen Maschine hergestellt werden, können die Qualitätsrisiken abgemildert werden.

Wenn man aber weltweit den Markt des Sondermaschinenbaus betrachtet, fällt auf, dass er von mittelständischen Familienbetrieben dominiert ist, die nur den lokalen oder regionalen Martkt bedienen. Lieferung und Service ins beziehungsweise im Ausland ist für diese Hersteller nicht zu leisten oder keine Kernstrategie.

Einige Maschinenhersteller haben dieses Problem erkannt und versprechen Abhilfe. Sie versuchen durch Gründung und strategischen Aufbau von Standorten oder auch durch Zukäufe von Unternehmen in Kernmärkten wie zum Beispiel in den USA oder China eine weltweit einheitliche Qualität der Maschinen zu gewährleisten. Noch ist das eher die Ausnahme als die Regel. Doch mit der fortschreitenden Globalisierung werden auch die Sondermaschinenbauer ihr Geschäft nicht mehr lange auf rein lokale oder regionale Geschäftsaktivitäten stützen können, wenn sie überleben wollen. Eine Konsolidierung des Markts ist hier in Kürze zu erwarten. 